\title{
Marketing goes Viral
}

$\mathrm{V}$

irales Marketing nutzt die Initiative von Kunden und Nutzern als Basis für eine laterale und vernetzte Kommunikation. Der Konsument emanzipiert sich aus seiner passiven Nutzerrolle und agiert als Sender und Empfänger einer Botschaft zugleich. Daraus entstehen Chancen: Die Unternehmenskommunikation kann dynamischer gestaltet werden, die Inhalte erscheinen authentischer und die gesendeten Botschaften gewinnen an Glaubwürdigkeit. Ebenso ergeben sich auch spezifische Herausforderungen: Ist ein Virus einmal gesetzt, kann auf den Verlauf der Epidemie kaum noch Einfluss genommen werden; eine aktive Steuerung des Kommunikationsprozesses ist dann nicht mehr möglich.

Virales Marketing sieht jedoch nur auf einen ersten flüchtigen Blick wie ein neuer Ansatz aus. Bereits in den siebziger Jahren des 20. Jahrhunderts setzten Unternehmen auf den sozialen Austausch zwischen Menschen: Die Methode des „Word-of-Mouth“ wurde genutzt, um relevante Kundengruppen zu erreichen und „Schneeballeffekte“ auszulösen. Noch heute ist das Konzept des Opinion-Leader-Marketing eines der Kernelemente klassischer Marketingstrategien in der Pharma-Branche.

Eine stärkere Anwendung und Verbreitung des viralen Marketing in aktuellen und zukünftigen Marketingstrategien von Unternehmen wird durch verschiedene Entwicklungen begünstigt.

Das Internet und seine Akzeptanz unterstützt den Übergang vom „Word-of-Mouth“ zum „Word-of-Mouse“: Interaktive Medien bilden die Basis, um Informationen, Meinungen und Inhalte in kürzester Zeit „viral“ zu verbreiten. Dazu leisten Social Networking und File Sharing Sites (z. B. YouTube, Flickr oder aber auch Tillate.ch) einen wichtigen Beitrag.

Zudem finden sich in der Praxis seit den frühen Ansätzen zu Beginn des Jahrtausends immer wieder eindrückliche Beispiele für erfolgreiche virale Kommunikationsstrategien. So haben nicht zuletzt Konzepte wie „The Tipping Point" von Malcolm Gladwell oder aber auch vermeintliche Best Practices wie das
„Moorhuhnspiel“ oder die Kampagne zum Film „Cloverfield“ dem viralen Marketing zu einer weiten Verbreitung in der Managementpraxis verholfen.

Darüber hinaus unterstützt die aktuelle wirtschaftliche Entwicklung eine kritische Bewertung der Marketingbudgets. So sehen Führungsverantwortliche im ,viralen Marketing “ erhebliche Effizienzpotenziale, die es für das eigene Unternehmen zu realisieren gilt.

Wenn auch diese, hier nur holzschnittartig, dargelegten Faktoren eine zunehmende Verbreitung des viralen Marketing in der Praxis unterstützen, so wird vielfach vernachlässigt, dass das Wissen über virale Prozesse, deren Wirkungsmechanismen oder auch deren Erfolgsvariablen noch in den Kinderschuhen steckt. Hier setzen die Beiträge der aktuellen Ausgabe der Marketing Review St. Gallen an. In bewährter Form befassen sich Autoren aus Praxis und Forschung mit spezifischen Herausforderungen viraler Kommunikation, analysieren den Einfluss und die Möglichkeiten des Web 2.0 für die Kundeninteraktion und zeigen anhand von aktuellen Beispielen viraler Kampagnen Erfolgspotenziale und Herausforderungen auf.

Wir bedanken uns an dieser Stelle sowohl bei den Autoren als auch bei den Gutachtern der Beiträge, die auch dieses Mal maßgeblich zum gelungenen Inhalt der Ausgabe beigetragen haben, und wünschen unseren Lesern interessante Anregungen sowie wertvolle Hinweise für ihre eigene Arbeit!

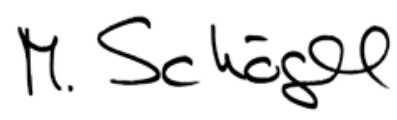

Prof. Dr. Marcus Schögel

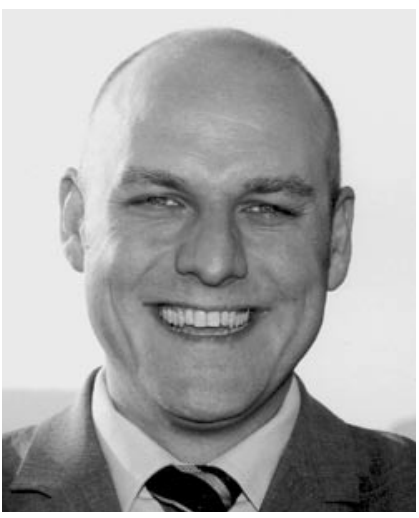

Prof. Dr. Marcus Schögel Direktor am Institut für Marketing an der Universität St. Gallen und Leiter des Kompetenzzentrums für Distribution und Kooperation E-Mail:marcus.schoegel@unisg.ch 